\title{
Research on the relationship between real estate industry and regional economic development in Underdeveloped Areas - Take Heyuan as an example
}

\begin{abstract}
Bai Yingchao ${ }^{1, a}$
${ }^{1}$ (School of Business, Macao University of Science and Technology; College of business administration, Heyuan Polytechnic)

abaiying168@163.com

Abstract

In recent years, with the well-known real estate development enterprises sinking into the third and fourth-tier cities, it is of great practical significance to study the relationship between the real estate industry and the economic development of the underdeveloped areas. In this paper, taking Heyuan City as the research object, the contribution of real estate industry to regional economic development is analyzed by principal component analysis and regression analysis. The results show that the real estate industry has a significant positive impact on the regional economic growth of Heyuan City, and each county should take measures according to local conditions to ensure the steady development of local real estate industry.
\end{abstract}

Key words: Real estate industry, Regional economy, Principal component analysis, Underdeveloped area

\section{INTRODUCTION}

In recent years, the well-known real estate enterprises, driven by the growth guarantee and encouraged by the national shed reform policy, gradually increase their efforts to sink into the third and fourth-tier cities. Therefore, the third and fourth-tier real estate industry suddenly ushered in the overall prosperity in the process of destocking, and the sales price of the third and fourth tier houses also ushered in a wave of rapid growth, even catching up with the minimum sales price of the secondtier cities. Under this background, it is of great practical significance to study the impact of the real estate industry on the underdeveloped third and fourth-tier regional economy.

\section{LITERATURE REVIEW}

After years of development, the real estate industry has become a pillar industry in China. In recent years, relevant scholars have carried out extensive research. $\mathrm{Hu}$ Jinxing and Gu Juan (2017) believe that the correlation between population aging and housing prices is different in areas with different economic development levels, and it is necessary to further improve China's population policy to make local governments play a greater role in stabilizing the real estate market [1]. Yang Huiyun and Li Guizhi (2017) took Anshan City as the research object, and put forward targeted solutions for the sustainable development of real estate in third-tier cities [2]. Zhong Changbiao (2018) thinks that some cities have high prices, high housing vacancy rate and the risk of real estate bubble deserves attention [3]. Wen Xijin (2018) put forward countermeasures from the factors of the problems in the real estate industry in the second and third-tier cities, and predicted the prospects of the real estate industry in the second and third-tier cities in China [4]. Zhang Jiahua (2018) believes that there are some problems in Meizhou real estate industry, such as high housing prices, excessive investment in financial resources, and squeezing the development of real economy, and so on. so we should strengthen the development of real economy through policy guidance [5]. Wang Xianzhu and Liu Caizhen (2018) proposed that from the coupling degree and coupling coordinated development degree of urban competitiveness and real estate industry, the first-tier cities are significantly higher than the second-tier cities, while the second-tier cities show a decreasing trend of high in the East and low in the west [6]. 
At present, the research on the real estate industry is mainly concentrated in the first and second-tier cities, while the research content focuses on population and real estate industry, destocking of real estate industry, coupling of real estate industry and regional economy, etc. Taking the underdeveloped city Heyuan as the research object, this paper uses the principal component analysis method, and makes regression analysis between the comprehensive development degree of real estate industry and GDP in Heyuan City, and discusses the contribution of real estate to local economic development. As Heyuan City belongs to the underdeveloped area in China's economically developed provinces, this paper can provide reference for the healthy development of the real estate industry in the third and fourth-tier cities in China.

\section{EMPIRICAL STUDY ON THE REAL ESTATE INDUSTRY AND ECONOMIC DEVELOPMENT IN HEYUAN CITY}

\subsection{Model selection}

In order to comprehensively analyze the relationship between real estate industry and economic development in Heyuan City, this paper puts forward several indicators that can reflect the development of real estate industry from different angles. At the same time, in order to solve the collinearity problem, this paper selects the principal component analysis method, and combines several indicators of real estate development with certain correlation into a new independent principal component, so as to analyze the influence of Heyuan real estate on regional economic development.

\subsection{Data sources}

The data of this paper comes from the statistical yearbook of Heyuan City from 2005 to 2018.

\subsection{Selection and arrangement of original data}

In order to fully reflect the comprehensive development of real estate industry in Heyuan City, this paper selects 12 indicators to build an index system. The index system includes Investment in real estate development, Land purchase fee, Buildings under construction this year, Buildings completed this year, Sales area of commercial housing, Value of buildings completed this year A Actual sales of commercial housing 、 New fixed assets of the year, Total output value of construction industry, Construction Engineering, Installation engineering, Purchase of equipment, tools and instruments.

\subsection{Data standardization and adaptability test}

Standardized data matrix can be obtained by standardizing the original data of different dimensions by SPSS24.0. The correlation matrix of each index variable shows that the correlation coefficient between variables is large, and principal component analysis can be used.

\subsection{Extraction and determination of principal components}

Through principal component analysis, the total variance interpretation table of the original data is obtained, as shown in Table 1. The eigenvalues of the first three components in Table 1 are 10.103, 1.485 and 0.187 , which explain $84.189 \%, 12.374 \%$ and $1.554 \%$ of the total variance of the original variables respectively. On this basis, in order to maximize the original data information, the first three principal components are selected to replace the original index system.

Table 1 explanation of total variance

\begin{tabular}{|c|c|c|c|c|c|c|}
\hline \multirow{2}{*}{$\begin{array}{l}\text { comp } \\
\text { onent }\end{array}$} & \multicolumn{3}{|c|}{ Initial eigenvalue } & \multicolumn{3}{|c|}{$\begin{array}{l}\text { Extract the load sum of } \\
\text { squares }\end{array}$} \\
\hline & total & $\begin{array}{c}\text { Variance } \\
\text { percentage }\end{array}$ & $\begin{array}{c}\text { Accumulat } \\
(\%)\end{array}$ & total & $\begin{array}{l}\text { Variance } \\
\text { percentage }\end{array}$ & $\begin{array}{c}\text { Accum } \\
\text { ulate } \\
(\%)\end{array}$ \\
\hline 1 & 10.103 & 84.189 & 84.189 & 10.103 & 84.189 & 84.189 \\
\hline 2 & 1.485 & 12.374 & 96.564 & 1.485 & 12.374 & 96.564 \\
\hline 3 & .187 & 1.554 & 98.118 & .187 & 1.554 & 98.118 \\
\hline 4 & .123 & 1.026 & 99.144 & & & \\
\hline 5 & .038 & .320 & 99.464 & & & \\
\hline 6 & .031 & .256 & 99.721 & & & \\
\hline 7 & .019 & .161 & 99.882 & & & \\
\hline 8 & .010 & .080 & 99.963 & & & \\
\hline 9 & .003 & .027 & 99.990 & & & \\
\hline 10 & .001 & .009 & 99.999 & & & \\
\hline 11 & $\begin{array}{c}7.651 \mathrm{E}- \\
5\end{array}$ & .001 & 99.999 & & & \\
\hline 12 & $\begin{array}{c}6.327 \mathrm{E}- \\
5\end{array}$ & .001 & 100.000 & & & \\
\hline & & & & & & \\
\hline
\end{tabular}




\subsection{Calculate the score of principal component and comprehensive development degree}

According to table 2, the calculation formula of each principal component is as follows:

$\mathrm{F} 1=0.099 \mathrm{X}_{1}+0.092 \mathrm{X}_{2}+0.098 \mathrm{X}_{3}+0.09 \mathrm{X}_{4}+0.096 \mathrm{X}_{5}+0$. $095 \mathrm{X}_{6}+0.096 \mathrm{X}_{7}+0.097 \mathrm{X}_{8}+0.097 \mathrm{X}_{9}+0.053 \mathrm{X}_{10}+0.071 \mathrm{X}_{11}$ $+0.094 \mathrm{X}_{12}$

$\mathrm{F} 2=-0.015 \mathrm{X}_{1}+0.001 \mathrm{X}_{2}+0.058 \mathrm{X}_{3}-0.067 \mathrm{X}_{4}-0.129 \mathrm{X}_{5^{-}}$ $0.146 \mathrm{X}_{6}-0.155 \mathrm{X}_{7}-0.074 \mathrm{X}_{8}-$

$0.051 \mathrm{X}_{9}+0.558 \mathrm{X}_{10}+0.448 \mathrm{X}_{11}+0.129 \mathrm{X}_{12}$

$\mathrm{F} 3=0.144 \mathrm{X}_{1}-1.675 \mathrm{X}_{2}+0.113 \mathrm{X}_{3}+0.283 \mathrm{X}_{4}+0.525 \mathrm{X}_{5}-$ $0.533 \mathrm{X}_{6}+0.468 \mathrm{X}_{7}-0.155 \mathrm{X}_{8}+0.616 \mathrm{X}_{9}+0.808 \mathrm{X}_{10^{-}}$ $0.735 \mathrm{X}_{11}+0.259 \mathrm{X}_{12}$

Taking the variance contribution rate of each principal component in Table 1 as the weight, we can comprehensively analyze the development of real estate industry in Heyuan City.

\section{$\mathrm{F}=0.84189 \mathrm{~F} 1+0.12374 \mathrm{~F} 2+0.01554 \mathrm{~F} 3$}

Table 2 component score coefficient matrix

\begin{tabular}{|c|c|c|c|}
\hline & \multicolumn{3}{|c|}{ component } \\
\hline & 1 & 2 & 3 \\
\hline Investment in real estate development & .099 & -.015 & .144 \\
\hline Land purchase fee & .092 & .001 & -1.675 \\
\hline Buildings under construction this year & .098 & .058 & .113 \\
\hline Buildings completed this year & .090 & -.267 & .283 \\
\hline Sales area of commercial housing & .096 & -.129 & .525 \\
\hline Value of buildings completed this year & .095 & -.146 & -.533 \\
\hline Actual sales of commercial housing & .096 & -.155 & .468 \\
\hline New fixed assets real estate in this year & .097 & -.074 & -.155 \\
\hline Total output value of construction industry & .097 & -.051 & .616 \\
\hline Construction Engineering & .053 & .558 & .808 \\
\hline Installation project & .071 & .448 & -.735 \\
\hline Purchase of equipment, tools and instruments & .094 & .129 & .259 \\
\hline $\begin{array}{l}\text { Extraction method: principal component analys } \\
\text { Component score. }\end{array}$ & & & \\
\hline
\end{tabular}

In the formula, F1, F2 and F3 are the principal component scores, and $\mathrm{F}$ is the score of comprehensive development degree of real estate industry in Heyuan City. Substituting the data, we can get the comprehensive development score of real estate industry in Heyuan City, as shown in Table 3 .
Table 3 comprehensive development degree of real estate industry in Heyuan City

\begin{tabular}{|c|c|c|c|c|}
\hline year & $F 1$ & $F 2$ & $F 3$ & $F$ \\
\hline 2004 & -1.08243 & -.78649 & .33500 & -1.0034 \\
\hline 2005 & -1.00772 & -.57095 & .42376 & -0.91245 \\
\hline 2006 & -.79590 & -.14928 & .44528 & -0.68161 \\
\hline 2007 & -.57547 & -.03595 & .67747 & -0.4784 \\
\hline 2008 & -.68512 & -.38328 & .07019 & -0.62313 \\
\hline 2009 & -.65362 & -.13585 & .37948 & -0.56119 \\
\hline 2010 & -.63216 & .15113 & .56445 & -0.50474 \\
\hline 2011 & -.04385 & -.11557 & -2.66857 & -0.09269 \\
\hline 2012 & .01300 & -.03034 & -1.78695 & -0.02058 \\
\hline 2013 & .32991 & .64861 & -.16195 & 0.35549 \\
\hline 2014 & .44078 & 1.31626 & .30493 & 0.538701 \\
\hline 2015 & .89676 & 1.59832 & .89869 & 0.966715 \\
\hline 2016 & 1.55262 & .97682 & -.06329 & 1.427023 \\
\hline 2017 & 2.24320 & -2.48342 & .58151 & 1.590266 \\
\hline
\end{tabular}

According to the data in Table 3, from 2004 to 2017, the overall trend is on the rise, and the development level of real estate industry in Heyuan City is constantly improving, especially in 2013 and 2014. As a result, the comprehensive development degree of real estate industry in Heyuan increased obviously.

\subsection{Analysis conclusion of the relationship between real estate industry and economic development in Heyuan City}

In order to quantitatively analyze the impact of Heyuan real estate industry on regional economy, $\mathrm{X}$ represents the comprehensive development degree of real estate industry and Y represents the regional GDP, and regression analysis is carried out.

Regression analysis showed that, $\mathrm{R} 2=0.943$, After adjustment $\mathrm{R} 2=0.938$, The data fit well with the model, The T value was 30.962, Sig=0,Pass the $\mathrm{t}$ test, The value of $\mathrm{f}$ is equal to 197.965 , $\mathrm{Sig}=0$, The regression coefficient reached significant level and the regression equation was valid.

The regression coefficient reached a significant level, and the regression equation was valid:

\section{$\mathrm{Y}=5333162.659+2955067.828 \mathrm{X}$}

The equation shows that the comprehensive development degree of real estate industry in Heyuan City is positively related to the regional GDP, and the GDP will increase by $29,550,678,280$ yuan for every $1 \%$ 
increase in the comprehensive development degree of real estate industry.

\section{POLICY SUGGESTIONS ON THE DEVELOPMENT OF REAL ESTATE INDUSTRY IN HEYUAN CITY}

\subsection{Clarify the regional status of the real estate industry}

The real estate industry is an important pillar industry in China, and it is also an important source of financial revenue in less developed areas. Therefore, less developed areas are easy to form the dependence of real estate industry. All counties and districts in Heyuan City need to make clear the regional status of the real estate industry, which is an important industry to promote urbanization and improve people's living standards. Therefore, all counties and districts in Heyuan City should evaluate their own population situation, economic development level and future city status, estimate the development scale of regional real estate industry, and promote the stable, orderly and healthy development of regional real estate industry.

\subsection{Using the old reform policy to improve the regional living standard}

As an underdeveloped mountainous city, Heyuan City has many old residential areas in its counties, districts and towns, which affect people's living standards. Therefore, all counties and districts should continue to strive for the support of the old reform policy, improve the land utilization rate and improve the living environment through the old reform. In the aspect of rehousing, it is suggested to consider the ratio of local house price to income. We can consider housing rehousing as the main factor, and monetary rehousing as the auxiliary factor, so as to stabilize local house price and residents' psychological expectation, and avoid the old reform becoming the main driver of house price rise.

\subsection{All counties and districts should take measures according to local conditions and cities}

The hot areas of real estate investment in Heyuan City are Yuancheng District and Longchuan County. Therefore, these two counties should seize the opportunity and make a good local urban construction plan to ensure the sustainable and healthy development of local real estate. Heyuan City should speed up the construction of Jiangdong New District, and promote the development of real estate industry around Yuancheng District by promoting the construction of the starting area, industrial park and commercial residential supporting facilities in Jiangdong New District. Other counties and districts in Heyuan City should plan scientifically to realize the coordination between local real estate industry and local economic and social development according to urban conditions. In a word, counties and districts should maintain moderate and healthy development of real estate, and avoid overstocking caused by rapid development, which will drag down local economic development.

\subsection{Encourage township residents to settle in cities and improve the housing security system}

As a mountainous city, the counties and districts of Heyuan City should further encourage remote mountainous areas and capable township residents to settle in the city, so as to promote the development of local urbanization. All counties and districts should improve the housing security system, integrate low rent housing, public rental housing, affordable housing multiple means to ease the worries of farmers into the city. In addition, all counties and districts should combine the advantages of local products, industry and natural culture, focus on the development of green industrial economy with local characteristics, provide full employment opportunities for urban farmers, and ensure the transformation of farmers into urban residents.

\section{CONCLUSION}

Based on principal component analysis, this paper analyzes the contribution of real estate industry to regional economic development in Heyuan City. This study shows that there is a positive correlation between the real estate industry and the regional economy in Heyuan City. The development of the real estate industry in Heyuan city promotes the growth of the regional economy. Heyuan City should take appropriate measures to ensure the steady development of the local real estate industry. In addition, this paper also provides reference for the healthy development of real estate industry in third--tier and fourth-tier cities in China.

\section{ACKNOWLEDGMENTS}

This work was financially supported by the project of Heyuan Social Development Science and Technology Plan Project "Research on the Driving Effect of Heyuan Real Estate Industry on Regional Economy Based on SPSS" (2018-56), Guangdong Provincial Department of Education's characteristic innovation project "Research on Industrial Agglomeration and Spatial Spillover Effect in Pearl River Delta Region under the Background of Guangdong-Hong Kong-Macao Greater Bay Area" (2019GWTSCX097), Heyuan Philosophy and Social Science Planning Project "Study on Coordinated Development of Real Estate Industry and Regional Economy in Heyuan City" (HYSK17P03). 


\section{REFERENCES}

[1] Hu Jinxing, Gu Juan. Regional heterogeneity of the impact of population aging on housing prices: An Empirical Analysis Based on panel data of 31 provinces in China [J]. Journal of East China Normal University (PHILOSOPHY AND SOCIAL SCIENCES EDITION), 2017, (03): 155-160 + 176.

[2] Yang Huiyun, Li Guizhi, Shi Hongyuan. Research on real estate problems and Countermeasures of third tier cities in Liaoning Province [J]. Economist, 2017, (08): 189-190.

[3] Zhong Changbiao. How to develop real estate in third tier cities? -- Based on the sample of Changde City [J]. Financial economy, 2018, (04): 40-42.

[4] Wen Xijin. Analysis on the current situation and Prospect of real estate development in second and third tier cities in China [J]. Modern marketing (Chuangfu information edition), 2018, (09): 45.

[5] Zhangjiahua. Research on real estate development in underdeveloped areas of Guangdong -- a case study of Meizhou [J]. Journal of Jiaying University, 2018, (01): 53-57.

[6] Wang Xianzhu, Liu Caizhen. Analysis on the spatial and temporal characteristics of the coupling and coordinated development of urban competitiveness and real estate industry -- An Empirical Study Based on 35 large and medium-sized cities in China [J]. East China economic management, 2018, (05): 7683. 